\title{
Glucose Suppression of Insulin Secretion in Chronically Hyperglycemic Fetal Sheep
}

\author{
THOMAS D. CARVER, SUSAN M. ANDERSON, PETER A. ALDORETTA, ANNE L. ESLER, AND \\ WILLIAM W. HAY JR. \\ Division of Perinatal Medicine and Research [T.D.C., S.M.A., P.A.A., W.W.H.] and the Department of \\ Biometrics [A.L.E.], University of Colorado School of Medicine, Denver, Colorado, 80262
}

\begin{abstract}
Previous observations in fetal sheep indicate that glucose may inhibit as well as enhance insulin secretion. To study conditions involved in inhibition of insulin secretion, we compared changes in plasma insulin concentration in response to acute increases in glucose and arginine concentrations in a group of normal, late gestation fetal sheep (euglycemic controls, EC) and a comparable group made chronically hyperglycemic by constant maternal glucose infusion (hyperglycemics, HG). After 7-10 d of maternal and fetal hyperglycemia, fetal glucose concentrations $(G)$ were significantly increased in the HG group $(0.98 \pm 0.07 \mathrm{mM} \mathrm{EC}$, $2.00 \pm 0.11 \mathrm{mM} \mathrm{HG}, p<0.001)$ but fetal plasma insulin concentrations $(l)$ were not significantly different $(57 \pm 7 \mathrm{pM}$ $\mathrm{EC}, 71 \pm 9 \mathrm{pM} \mathrm{HG}, p=0.2$ ). Furthermore, the $\mathrm{I} / \mathrm{G}$ ratio was significantly decreased in the HG group $(60 \pm 9 \mathrm{EC}, 40 \pm 4 \mathrm{HG}$, $p=0.03)$ and during a hyperglycemic glucose clamp $(\Delta G \cong 1.4$ $\mathrm{mM}$ ), glucose-stimulated increase in steady state $I$ was less in the HG than in the EC fetuses (mean $\Delta I / \Delta G=106 \pm 15 \mathrm{EC}, 61 \pm$ $10 \mathrm{HG}, p=0.01$ ). An arginine infusion at the end of the clamp produced similar increases in $I$ in the $\mathrm{EC}$ and $\mathrm{HG}$ groups $(\Delta I=$ $824 \pm 116 \mathrm{pM} \mathrm{EC}, 906 \pm 131 \mathrm{pM} \mathrm{HG}, p=0.45)$. There were no differences between groups for blood oxygen saturation and content, $\mathrm{pH}$, or lactate concentration. After 14-17 d of hyper-
\end{abstract}

\section{ABSTRACT}

glycemia, glucose-stimulated increase in $I$ was even more reduced in the $\mathrm{HG}$ fetuses than observed at 7-10 d. Decreased insulin response to arginine also was present, although pancreatic insulin concentration was not decreased. Glucose-stimulated increase in $I$ returned to normal after $7 \mathrm{~d}$ of no glucose infusion and euglycemia. These data indicate that glucose-stimulated insulin secretion is reversibly decreased by marked, chronic hyperglycemia. Because pharmacologic inhibitors of insulin secretion (e.g. streptozotocin or alloxan) were not used, and oxygenation, $\mathrm{pH}$, and lactate values were similar between the two groups, this decrease of insulin secretion appears to be glucose-specific, although mechanisms involved can include both glucose and amino acid (arginine) stimulation processes. Such decrease in fetal insulin secretion may limit the rate of fetal glucose utilization during chronic hyperglycemia and thereby modulate the rate of fetal growth. (Pediatr Res 38: 754-762, 1995)
EC, euglycemic controls
HG, hyperglycemics
$G$, glucose concentration
$I$, insulin concentration

Attempts to mimic the gestational diabetic state in animal models, particularly in sheep, have produced mixed responses with respect to the relationships between the magnitude and duration of changes in fetal plasma glucose concentration and fetal insulin secretion. Insulin secretion in fetal sheep in response to acute hyperglycemia has been reported to occur as early as $110 \mathrm{~d}(73 \%)$ gestation, and in late gestation it has the same dose-response kinetics as observed in adult ewes, although at lower glucose and insulin concentrations and without a first phase response $(1,2)$. In contrast, streptozotocin- and

Received November 29, 1995; accepted May 28, 1995.

Correspondence: William W. Hay, Jr., M.D., Box B-195, University of Colorado School of Medicine, 4200 E. Ninth Avenue, Denver, CO 80262.

Supported by National Institutes of Health grants DK35836 and HD20761. P.W.A. was supported by National Institutes of Health Training Grant HD07186. Maj. Thomas D. Carver is supported by the U.S. Army Medical Corps.

The opinions expressed in this article are those of the authors and do not necessarily reflect those of the U.S. Army or the Department of Defense. alloxan-induced maternal hyperglycemia in pregnant sheep have produced sustained fetal hyperglycemia but not sustained fetal hyperinsulinemia $(3,4)$. The secretion of insulin in response to further hyperglycemia, a measure of pancreatic $\beta$-cell responsiveness and insulin secretion capacity (in contrast to decreased insulin synthesis or increased insulin disappearance), was not tested in these hyperglycemic models. Another study in fetal sheep, however, showed that fetal insulin concentration, which initially increased during continuous glucose infusions, later decreased; furthermore, the insulin response to further increases in glucose concentration appeared to decrease, especially toward the end of $5 \mathrm{~d}$ of hyperglycemia (5). In most of the animals in these and other studies $(6,7)$, the glucose concentrations were quite high, and when measured, the blood oxygen contents often were quite low, in the range often associated with high placental catecholamine concentrations $(8,9)$, indicating that some of these 
animals were physiologically unstable, potentially producing multifactorial changes in the relationship between glucose concentration and insulin secretion. Together, however, these observations demonstrate a down-regulation of fetal pancreatic insulin secretion that may have been induced over time by glucose itself, or by some other factor that developed during the persistent hyperglycemia, or both. Such a condition could limit fetal glucose utilization, at least by insulin-sensitive tissues, and thereby modulate the rate of fetal growth.

Based on these mixed observations we hypothesized that persistent, marked hyperglycemia in fetal sheep would suppress basal insulin secretion to normal rates and decrease insulin secretion in response to further hyperglycemia. Furthermore, such changes in insulin secretion would be dependent on the duration of the hyperglycemia and would be specific to glucose. The present study tested these hypotheses by comparing the acute glucose-induced increase in insulin concentration, an index of fetal pancreatic insulin secretion, in late gestation euglycemic fetal sheep with that in fetal sheep of the same gestational age that were made chronically hyperglycemic by maternal dextrose infusions for variable periods of up to $17 \mathrm{~d}$. Reversibility was studied in some animals that were returned to euglycemia to test further for the specificity of the hyperglycemic condition as a cause of decreased insulin secretion and because of the possibility that prenatal inhibition of pancreatic function may have prolonged effects on pancreatic development (10). Comparisons of insulin secretion to arginine also were made to test whether the suppression of insulin secretion by hyperglycemia affected only mechanisms of insulin secretion that directly and specifically involved glucose (11).

\section{METHODS}

Columbia-Rambouillet ewes of known gestational age were studied. Surgery was performed at 113-125-d gestation to place indwelling 20 gauge polyvinyl catheters into the fetal and maternal arterial and venous circulations. The animals were anesthetized with either pentobarbital sedation $(15 \mathrm{mg} / \mathrm{kg})$ and tetracaine hydrochloride spinal anesthesia $(10 \mathrm{mg})$, or alternatively with i.v. ketamine anesthesia $(12-15 \mathrm{mg} / \mathrm{kg}$ bolus induction, with $0.3-0.5 \mathrm{mg} / \mathrm{min} / \mathrm{kg}$ continuous maintenance infusion) and intramuscular acepromazine $(1 \mathrm{mg} / \mathrm{kg})$ and diazepam (10 $\mathrm{mg}$ ) for muscle relaxation and sedation. The ewe and fetus were also treated with $1 \%$ lidocaine local anesthesia when needed. At the time of surgery intramuscular streptomycin (1 $\mathrm{g})$ or gentamicin $(80 \mathrm{mg})$ and procaine penicillin $\mathrm{G}(600000$ $\mathrm{U})$ were given to the ewe, followed by intra-amniotic ampicillin (500 mg) at the end of surgery. After the surgery each ewe was kept in a cart and allowed ad libitum access to alfalfa pellets, water, and a mineral block. The amount of food consumed was recorded daily for each ewe. Each ewe received a weekly 5-mL intramuscular injection of a multivitamin preparation (B-complex vitamins, Vedco, St. Joseph, MO). Because of the flocking nature of sheep at least two ewes were maintained in the same room at all times to reduce potential psychologic stress. The rooms were computer-controlled to maintain a temperature of $21^{\circ} \mathrm{C}$ with $18 \mathrm{~h}$ of variable light and $6 \mathrm{~h}$ of darkness daily. The catheters were flushed daily with
1.5-3.0 mL of a heparinized saline solution (150 $\mathrm{U}$ of heparin per $\mathrm{mL}$ of $0.9 \%$, wt/vol, $\mathrm{NaCl}$ in $\mathrm{H}_{2} \mathrm{O}$ ). The animals were allowed to recover from surgery for $4 \mathrm{~d}$ before any fetal studies. At the end of the studies each ewe and fetus was killed with an i.v. euthanasia solution (Sleepaway ${ }^{\mathrm{TM}}$, sodium pentobarbital in 10\% alcohol, Fort Dodge Laboratories Inc, Fort Dodge IA). All studies, animal surgery, and animal maintenance procedures were approved by the University of Colorado Health Sciences Center Institutional Animal Care and Use Committee.

\section{STUDY DESIGN}

After recovery, samples for blood glucose, plasma insulin, blood hematocrit, blood oxygen saturation and content, $\mathrm{pH}$, and lactate were obtained from each ewe and fetus to determine physiologic stability. The animals were randomly assigned to either a euglycemic control group (EC, $n=12$ ) or a chronically hyperglycemic group ( $\mathrm{HG}, n=21)$. A hyperglycemic glucose clamp of 150-min duration was then performed in each fetus (Fig. 1, top panel; this was study 1). This study was designed to evaluate fetal insulin secretion, measured as the change in fetal plasma insulin concentration in response to an acute and sustained increase in fetal glucose concentration of about $1.4 \mathrm{mM}$ above the zero time concentration (about 1.0 $\mathrm{mM}$ ) using a primed, variable infusion of $20 \%$, wt/vol, dextrose in $\mathrm{H}_{2} \mathrm{O}$. After $120 \mathrm{~min}$, eight of the fetuses received a supplemental 5-min infusion of arginine free base of $0.18-$ $0.20 \mathrm{mmol} / \mathrm{kg}$ estimated fetal weight $(1.25 \mathrm{~g}$ in $9.0 \mathrm{~mL}$ of $0.9 \%$ saline with $2.0 \mathrm{~mL}$ of $2.0 \mathrm{~N}$ acetic acid to bring the $\mathrm{pH}$ to 8 ). Based on preliminary trials, this pharmacologic dose of arginine in fetal sheep in late gestation produces a maximum response of insulin secretion to arginine (12). The hyperglycemic glucose clamp was continued, and blood samples were collected between 125 and $150 \mathrm{~min}$.

Following study 1 , the ewes that were assigned to the $\mathrm{HG}$ group were made chronically hyperglycemic (Fig. 1, bottom panel) by continuous variable infusions of $50 \% \mathrm{wt} / \mathrm{vol}$ dextrose in $\mathrm{H}_{2} \mathrm{O}\left(\mathrm{D}_{50} \mathrm{~W}\right)$. The maternal and fetal glucose concentrations were measured once or twice daily and the $\mathrm{D}_{50} \mathrm{~W}$ infusions were adjusted to maintain maternal blood glucose concentrations between 4.2 and $5.6 \mathrm{mM}$ (euglycemia in pregnant sheep is $2.5-3.1 \mathrm{mM}$ ). After 7-10 d, a second fetal hyperglycemic clamp was performed in 19 of the $21 \mathrm{HG}$ fetuses and all 12 of the EC fetuses (loss of animals due to catheter obstruction); this was study 2 or "7-10-d" study. The fetal blood glucose concentration was acutely increased by about $1.4 \mathrm{mM}$ above the "time 0 " concentration at the start of the clamp and maintained for $150 \mathrm{~min}$. Arginine was then administered by bolus injection between 120 and $125 \mathrm{~min}$ in all 19 of the $\mathrm{HG}$ fetuses and 6 (randomly selected) of the EC fetuses. Immediately after this 150 -min clamp, the remaining 6 fetuses in the EC group underwent a second hyperglycemic clamp period that produced a further increase in glucose concentration of about $1.4 \mathrm{mM}$ for an additional $120 \mathrm{~min}(120-240 \mathrm{~min}$ of study 2). This second clamp in these animals was done to evaluate the short-term effects of further hyperglycemia on fetal insulin secretion in normal animals and to determine the 

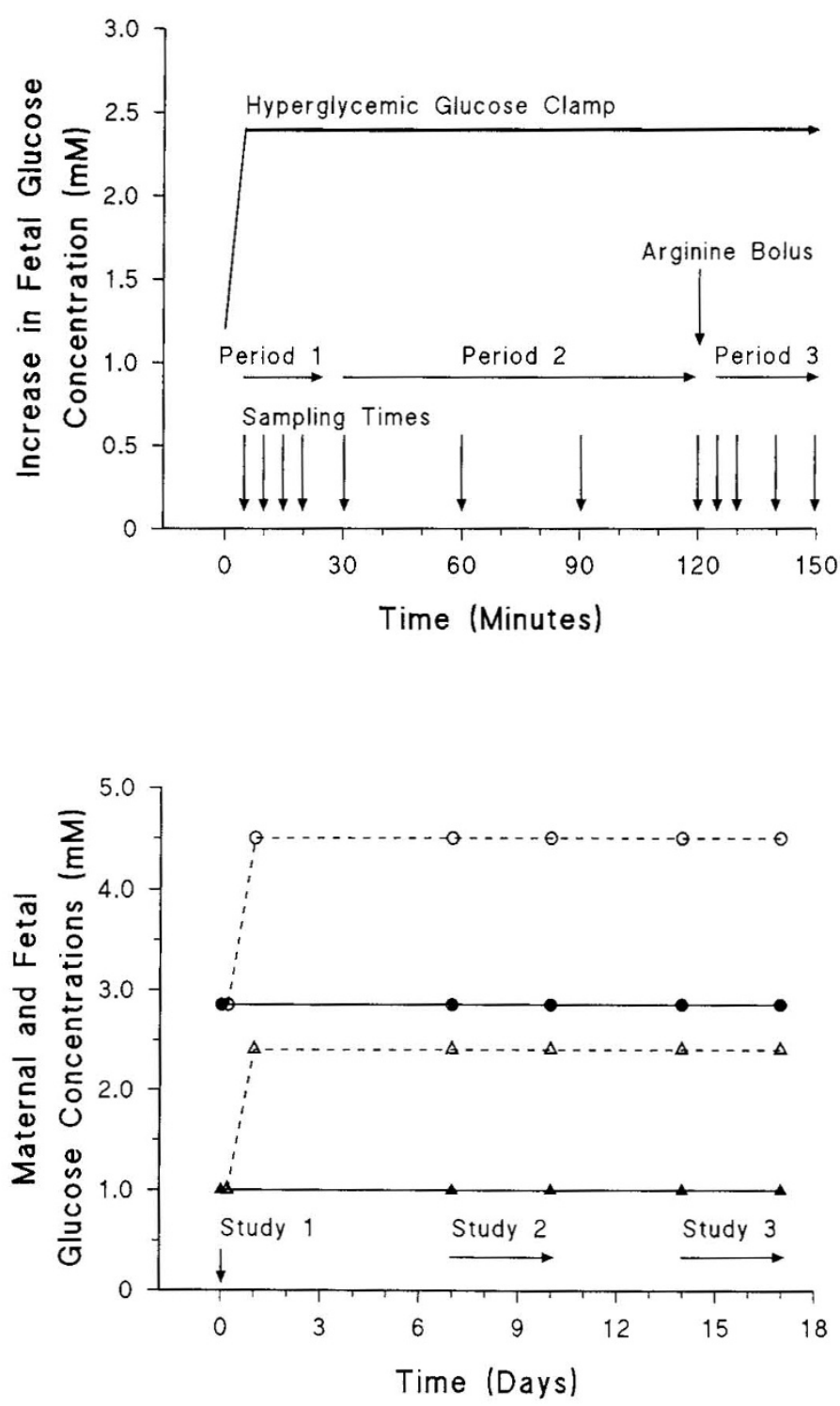

Figure 1. (Top) Time course of periods 1,2 , and 3 during each of the hyperglycemic clamps showing the expected changes in fetal glucose concentration, the time of the arginine bolus, and the sampling times. (Bottom) Time course of studies 1,2 , and 3 and the expected changes in maternal $(\bullet)$ EC; 90 , HG) and fetal $(\boldsymbol{\Lambda}, E C ; \triangle, H G)$ glucose concentrations. Each animal was studied only once on only $1 \mathrm{~d}$ for studies 2 and 3 .

glucose-insulin dose response relationship in normal fetuses over the range of glucose concentrations studied in both the EC and $\mathrm{HG}$ animals.

After study 2 chronic maternal glucose infusions were successfully continued in $6 \mathrm{HG}$ ewes (randomly selected from the HG group) for an additional 5-8 d (again, loss of animals due to catheter failure). These six sheep and eight control sheep (also randomly selected from the control group) were then studied by the same hyperglycemic glucose clamp and bolus arginine infusion (study 3 or "14-17-d" study) to test for persistence of changes produced by chronic hyperglycemia.

Also after the second study, maternal glucose infusions were discontinued in six other HG ewes (randomly selected from the HG group) and after $7 \mathrm{~d}$ an additional hyperglycemic glucose clamp study was performed to test for reversibility of the effects produced by chronic hyperglycemia.

\section{BIOCHEMICAL ANALYSIS}

At timed intervals during the glucose clamps $\left(0^{\prime}, 0^{\prime \prime}, 5,10\right.$, $15,20,30,60,90,120,125,130,140$, and $150 \mathrm{~min}$ ), samples were collected in EDTA-lined syringes to measure whole blood glucose, lactate, arginine, and plasma insulin concentrations. At $0^{\prime}, 0^{\prime \prime}, 60,120,125$, and $150 \mathrm{~min}$, blood also was collected into heparinized Caraway glass capillary tubes to measure blood $\mathrm{pH}$, oxygen saturation, and oxygen content.

Whole blood glucose and lactate concentrations were measured with a YSI model 23 A analyzer (Yellow Springs Instrument Company, Yellow Springs, $\mathrm{OH}$ ). The blood for plasma insulin was immediately centrifuged at $4^{\circ} \mathrm{C}$ for $3 \mathrm{~min}$ and the plasma was stored at $-70^{\circ} \mathrm{C}$ until analyzed using the double antibody separation technique with a Ventrex ${ }^{125}$ I-RIA kit (Ventrex Laboratories Inc., Portland, ME). The sensitivity of these kits is $12 \mathrm{pM}$. The intra- and interassay variability were both $<10 \%$ over the course of these studies. At the time of necropsy, fetal and maternal pancreas tissue were placed in $0.01 \mathrm{~N} \mathrm{HCl}$ and frozen at $-70^{\circ} \mathrm{C}$ until analyzed for insulin content using methodology previously reported $(13,14)$.

Blood oxygen saturation and content were measured with an OSM III Hemoximeter (Radiometer, Copenhagen, Denmark). $\mathrm{pH}$ was determined using an ABL 330 blood gas analyzer (Radiometer, Copenhagen, Denmark). Blood arginine concentrations were measured with a Beckman 6300 amino acid analyzer (Beckman Instruments Inc., Fullerton, CA).

\section{DATA ANALYSIS}

All results are reported as the mean \pm SEM unless otherwise noted. Mean values for each variable were calculated from samples obtained at time zero before the start of the clamp (duplicates), from 5-25 min of the clamp (period 1), from $30-120 \mathrm{~min}$ (period 2), and from $125-150 \mathrm{~min}$ (period 3) for all animals during a given study (Fig. 1, top panel), and from $135-240$ min of period 3 in study 2 for the six EC animals studied with a continued hyperglycemic clamp. Period 1,2 , and 3 values for the change in glucose concentration $(\Delta G)$ were calculated as the period mean value minus the mean zero time value. Period 1 and 2 values for the change in insulin concentration $(\Delta l)$ were calculated as the period mean value minus the mean zero time value. Period 3 (arginine infusion period) $\Delta I$ represents the period 3 mean insulin concentration minus the mean insulin concentration during period $2(30-120 \mathrm{~min})$. For the six EC animals studied with a second glucose clamp in study 2, period $3 \Delta G$ and $\Delta I$ represent period 3 mean values for $G$ and $I$ minus period 2 mean values for $G$ and $I$, respectively. These calculations were determined after results showed that period 2 values for glucose and insulin concentrations were in steady state, defined as less than a $\pm 5 \%$ difference of individual values around the period mean value with no consistent trend over the period for values to increase or decrease. The ratio of absolute insulin concentration to glucose concentration $(I / G)$ and the ratio of change in insulin concentration to change in glucose concentration $(\Delta I / \Delta G)$ were calculated to account for different values of $G$ among animals within a group and between groups based on previous observations in fetal sheep of a direct relationship between $I$ and $G, \Delta I$ and $\Delta G$, and the 

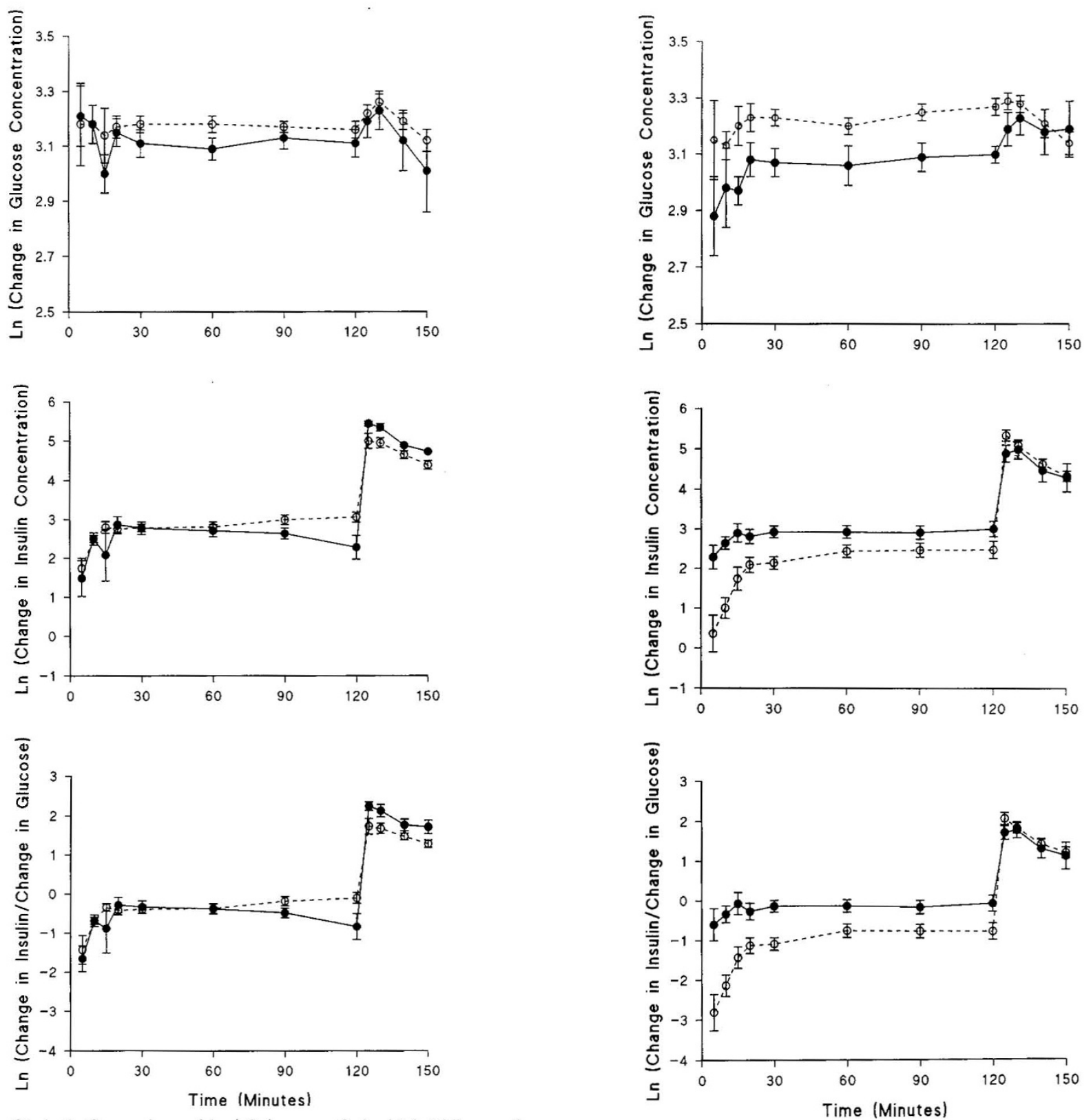

Figure 2. Study 1: Comparison of In $\Delta G$ (top panel), ln $\Delta I$ (middle panel), and $\ln \Delta l / \Delta G$ ratio (bottom panel) at each sampling time during period $1(5-25$ $\mathrm{min})$, period $2(30-120 \mathrm{~min})$, and period $3(125-150 \mathrm{~min})$ for the control $(\bullet)$ and hyperglycemic animals $(O)$. Data are shown as mean \pm SEM.

Figure 3. Study 2: Comparison of $\ln \Delta G$ (top panel), $\ln \Delta I$ (middle panel), and $\ln \Delta I / \Delta G$ ratio (bottom panel) at each sampling time during period 1 (5-25 $\mathrm{min})$, period $2(30-120 \mathrm{~min})$, and period $3(125-150 \mathrm{~min})$ for the control and hyperglycemic animals $(O)$. Data are shown as mean \pm SEM.

Table 1. Mean \pm SEM values for biochemical and hematologic variables from duplicate samples obtained at time zero of each glucose clamp study (gestational age values are mean $\pm S D$ )

\begin{tabular}{|c|c|c|c|c|c|c|}
\hline \multirow[b]{2}{*}{ Variable } & \multicolumn{2}{|c|}{ Study 1} & \multicolumn{2}{|c|}{ Study 2} & \multicolumn{2}{|c|}{ Study 3} \\
\hline & $\begin{array}{l}\text { Control } \\
(n=12)\end{array}$ & $\begin{array}{l}\text { Hyperglycemic } \\
(n=21)\end{array}$ & $\begin{array}{l}\text { Control } \\
(n=12)\end{array}$ & $\begin{array}{c}\text { Hyperglycemic } \\
(n=19)\end{array}$ & $\begin{array}{l}\text { Control } \\
(n=8)\end{array}$ & $\begin{array}{c}\text { Hyperglycemic } \\
(n=6)\end{array}$ \\
\hline Gestational age (d) & $122 \pm 1$ & $122 \pm 1$ & $130 \pm 1$ & $130 \pm 1$ & $137 \pm 1$ & $138 \pm 1$ \\
\hline Glucose $_{\text {maternal }}(\mathrm{mM})$ & $2.79 \pm 0.05$ & $2.95 \pm 0.19$ & $2.72 \pm 0.14$ & $4.50 \pm 0.17^{* *}$ & $2.81 \pm 0.05$ & $4.25 \pm 0.20 * *$ \\
\hline $\operatorname{Glucose}_{\text {fetal }}(\mathrm{mM})$ & $1.02 \pm 0.05$ & $1.02 \pm 0.04$ & $0.98 \pm 0.07$ & $2.00 \pm 0.11^{* *}$ & $0.99 \pm 0.08$ & $1.73 \pm 0.13^{* *}$ \\
\hline Insulin $(\mathrm{pM})$ & $60.4 \pm 9.6$ & $62.1 \pm 6.9$ & $57.1 \pm 7.3$ & $71.2 \pm 8.8$ & $57.5 \pm 8.3$ & $37.4 \pm 7.3$ \\
\hline$I / G$ & $60.0 \pm 11.0$ & $59.9 \pm 5.4$ & $60.0 \pm 8.6$ & $39.7 \pm 4.3$ & $56.8 \pm 5.4$ & $22.5 \pm 5.3$ \\
\hline $\mathrm{O}_{2}$ saturation $(\%)$ & $52.2 \pm 2.9$ & $58.6 \pm 2.4$ & $47.9 \pm 4.4$ & $53.3 \pm 2.4$ & $50.5 \pm 2.8$ & $48.0 \pm 4.6$ \\
\hline $\mathrm{O}_{2}$ content $(\mathrm{mM})$ & $3.54 \pm 0.22$ & $3.43 \pm 0.14$ & $3.55 \pm 0.20$ & $3.08 \pm 0.15$ & $3.22 \pm 0.24$ & $3.02 \pm 0.42$ \\
\hline $\mathrm{pH}$ & $7.33 \pm 0.01$ & $7.33 \pm 0.01$ & $7.34 \pm 0.02$ & $7.33 \pm 0.01$ & $7.33 \pm 0.01$ & $7.33 \pm 0.01$ \\
\hline Lactate (mM) & $1.32 \pm 0.13$ & $1.34 \pm 0.09$ & $1.29 \pm 0.11$ & $1.67 \pm 0.10^{* *}$ & $1.41 \pm 0.15$ & $1.47 \pm 0.07$ \\
\hline
\end{tabular}

${ }^{* *} p<0.01$, hyperglycemic different from control during same study. 
Table 2. Study 1 glucose clamp: steady state period mean \pm SEM values for biochemical and hematologic variables

\begin{tabular}{|c|c|c|c|c|c|c|}
\hline \multirow[b]{2}{*}{ Variable } & \multicolumn{2}{|c|}{ Period $1(5-25 \mathrm{~min})$} & \multicolumn{2}{|c|}{ Period $2(30-120 \mathrm{~min})$} & \multicolumn{2}{|c|}{ Period $3(125-150 \mathrm{~min})$} \\
\hline & $\begin{array}{c}\text { Control } \\
(n=12)\end{array}$ & $\begin{array}{l}\text { Hyperglycemic } \\
(n=21)\end{array}$ & $\begin{array}{c}\text { Control } \\
(n=12)\end{array}$ & $\begin{array}{c}\text { Hyperglycemic } \\
(n=21)\end{array}$ & $\begin{array}{c}\text { Control } \\
(n=12)\end{array}$ & $\begin{array}{l}\text { Hyperglycemic } \\
\quad(n=12)\end{array}$ \\
\hline Glucose (mM) & $2.39 \pm 0.09$ & $2.41 \pm 0.10$ & $2.28 \pm 0.07$ & $2.36 \pm 0.05$ & $2.32 \pm 0.09$ & $2.46 \pm 0.08$ \\
\hline$\Delta$ Glucose $(\mathrm{mM})$ & $1.37 \pm 0.08$ & $1.38 \pm 0.08$ & $1.26 \pm 0.05$ & $1.33 \pm 0.03$ & $1.33 \pm 0.04$ & $1.37 \pm 0.04$ \\
\hline Insulin (pM) & $162 \pm 21$ & $153 \pm 13$ & $156 \pm 20$ & $192 \pm 18$ & $839 \pm 58$ & $855 \pm 100$ \\
\hline$\Delta$ Insulin $(\mathrm{pM})$ & $101 \pm 14$ & $91 \pm 9$ & $96 \pm 12$ & $130 \pm 15$ & $844 \pm 56$ & $791 \pm 94$ \\
\hline $\mathrm{O}_{2}$ saturation $(\%)$ & $54.6 \pm 2.8$ & $58.5 \pm 2.9$ & $51.0 \pm 2.9$ & $55.2 \pm 2.5$ & $49.8 \pm 0.30$ & $51.8 \pm 2.9$ \\
\hline $\mathrm{O}_{2}$ content $(\mathrm{mM})$ & $3.34 \pm 0.31$ & $3.49 \pm 0.30$ & $3.16 \pm 0.29$ & $3.46 \pm 0.26$ & $3.04 \pm 0.30$ & $3.27 \pm 0.31$ \\
\hline $\mathrm{pH}$ & $7.32 \pm 0.03$ & $7.35 \pm 0.03$ & $7.32 \pm 0.02$ & $7.33 \pm 0.03$ & $7.33 \pm 0.04$ & $7.34 \pm 0.04$ \\
\hline Lactate (mM) & $1.33 \pm 0.09$ & $1.34 \pm 0.10$ & $1.48 \pm 0.11$ & $1.47 \pm 0.12$ & $1.89 \pm 0.17^{* *}$ & $1.79 \pm 0.22^{*}$ \\
\hline
\end{tabular}

$* p<0.05$ hyperglycemic different from control, same period.

** $p<0.01$ hyperglycemic different from control, same period.

Table 3. Study 2 glucose clamp: steady state period mean \pm SEM values for biochemical and hematologic variables

\begin{tabular}{|c|c|c|c|c|c|c|}
\hline \multirow[b]{2}{*}{ Variable } & \multicolumn{2}{|c|}{ Period 1 (5-25 min) } & \multicolumn{2}{|c|}{ Period 2 (30-120 min) } & \multicolumn{2}{|c|}{ Period $3(125-150 \mathrm{~min})$} \\
\hline & $\begin{array}{c}\text { Control } \\
(n=10)\end{array}$ & $\begin{array}{c}\text { Hyperglycemic } \\
(n=19)\end{array}$ & $\begin{array}{c}\text { Control } \\
(n=10) \\
\end{array}$ & $\begin{array}{l}\text { Hyperglycemic } \\
(n=19)\end{array}$ & $\begin{array}{c}\text { Control } \\
(n=10) \\
\end{array}$ & $\begin{array}{l}\text { Hyperglycemic } \\
(n=12)\end{array}$ \\
\hline Glucose (mM) & $2.16 \pm 0.10$ & $3.34 \pm 0.12^{* *}$ & $2.20 \pm 0.05$ & $3.41 \pm 0.10^{* *}$ & $2.73 \pm 0.14$ & $3.57 \pm 0.10^{* *}$ \\
\hline$\Delta$ Glucose $(\mathrm{mM})$ & $1.18 \pm 0.08$ & $1.36 \pm 0.06^{*}$ & $1.22 \pm 0.05$ & $1.42 \pm 0.03^{* *}$ & $1.75 \pm 0.11$ & $1.57 \pm 0.05$ \\
\hline Insulin (pM) & $156 \pm 20$ & $118 \pm 14^{*}$ & $186 \pm 25$ & $157 \pm 20$ & $881 \pm 118$ & $986 \pm 131$ \\
\hline$\Delta$ Insulin $(\mathrm{pM})$ & $99 \pm 15$ & $46 \pm 10^{* *}$ & $129 \pm 20$ & $86 \pm 16^{*}$ & $824 \pm 116$ & $906 \pm 131$ \\
\hline $\mathrm{O}_{2}$ saturation $(\%)$ & $49.2 \pm 2.1$ & $53.4 \pm 2.0$ & $49.2 \pm 2.1$ & $50.2 \pm 3.0$ & $49.1 \pm 1.5$ & $49.0 \pm 2.1$ \\
\hline $\mathrm{O}_{2}$ content $(\mathrm{mM})$ & $3.46 \pm 0.21$ & $3.15 \pm 0.15$ & $3.26 \pm 0.19$ & $3.00 \pm 0.31$ & $3.10 \pm 0.30$ & $2.95 \pm 0.32$ \\
\hline $\mathrm{pH}$ & $7.34 \pm 0.02$ & $7.33 \pm 0.02$ & $7.31 \pm 0.01$ & $7.33 \pm 0.02$ & $7.30 \pm 0.02$ & $7.33 \pm 0.02$ \\
\hline Lactate $(\mathrm{mM})$ & $1.36 \pm 0.11$ & $1.67 \pm 0.20$ & $1.57 \pm 0.08$ & $1.96 \pm 0.21$ & $1.90 \pm 0.16$ & $2.20 \pm 0.14$ \\
\hline
\end{tabular}

$* p<0.05$ hyperglycemic different from control, same period.

** $p<0.01$ hyperglycemic different from control, same period.

potential for these relationships to be nonlinear over the range of glucose concentrations studied in the two groups of animals $(1,6,7,15)$.

\section{STATISTICAL ANALYSES}

Statistical analyses used a univariate mixed effects model analysis of variance appropriate for repeated measurements on each animal $(16,17)$. Specifically, groups (control and hyperglycemic) were considered fixed, between subject factors. Studies (study 1; study 2 or "7-10-d"; and study 3 or " $14-17$ d") and periods (period 1 from 5 to 25 min; period 2 from 30 to $120 \mathrm{~min}$; and period 3 from 125 to $150 \mathrm{~min}$ ) were considered fixed, within subject factors. Individual animals, nested within groups, were considered random. Regression analysis used a mixed effects model that assumed a compound symmetric covariance structure (16).

There was considerable variability among animals with respect to the actual period mean glucose concentration achieved and steady state insulin concentration measured in each period. Because of this variability, raw data also were natural log transformed to analyze the relative changes in glucose and insulin concentrations in each period between the two groups. The analyses were implemented via SAS Proc MIXED.

\section{RESULTS}

Table 1 shows biochemical and hematologic results obtained at time zero for control and hyperglycemic animals during the three studies. No differences between the EC and HG groups were noted in study 1 . In study 2 , time zero maternal and fetal glucose concentrations were significantly higher in the HG group ( $+65 \pm 6 \%$ maternal, $+98 \pm 11 \%$ fetal), as was the fetal/maternal glucose concentration ratio $(0.35 \pm 0.03$ in the EC group, $0.44 \pm 0.04$ in the HG group, $p=0.04$ ) and the fetal blood lactate concentrations $(+37 \pm 3.1 \%)$. At the time of study 3, time zero maternal and fetal glucose concentrations were significantly higher in the HG group ( $51 \pm 7 \%$ maternal, $74 \pm 13 \%$ fetal); the fetal/maternal glucose concentration ratio was not quite significantly increased in the HG group (0.35 \pm 0.03 in the EC group, $0.41 \pm 0.03$ in the HG group, $p=0.07$ ). Food intake was not different between the two groups of ewes (data not shown).

In study 1 (Table 2 and Fig 2), glucose and insulin concentrations and changes in glucose and insulin concentrations in the three periods were not different between the two groups. In both groups, blood $\mathrm{O}_{2}$ saturation and content tended to decline but not significantly during the glucose clamp, blood lactate concentration was significantly increased by the third period, and $\mathrm{pH}$ did not change significantly; there were no betweengroup differences for these variables.

During study 2 (7-10 d of hyperglycemia), $G$ and $\Delta G$ were greater in period 2 in the $\mathrm{HG}$ group compared with the $\mathrm{EC}$ group, whereas $\Delta I$ was less (Table 3). As shown in Figure 3, in spite of higher values of $\ln \Delta G$ in periods 1 and 2 in the $\mathrm{HG}$ group compared with the EC group $(p=0.003$ and $p=0.007$, respectively), $\ln \Delta I$ values in periods 1 and 2 were less in the HG group ( $p<0.001$ for period $1, p=0.0003$ for period 2$)$, as were the $\ln \Delta I / \Delta G$ ratios ( $p<0.0001$ for each period). After the arginine infusion in period $3, \ln \Delta I$ and $\ln \Delta I / \Delta G$ were not different between the two groups $(p=0.96$ and $p=0.76$, 

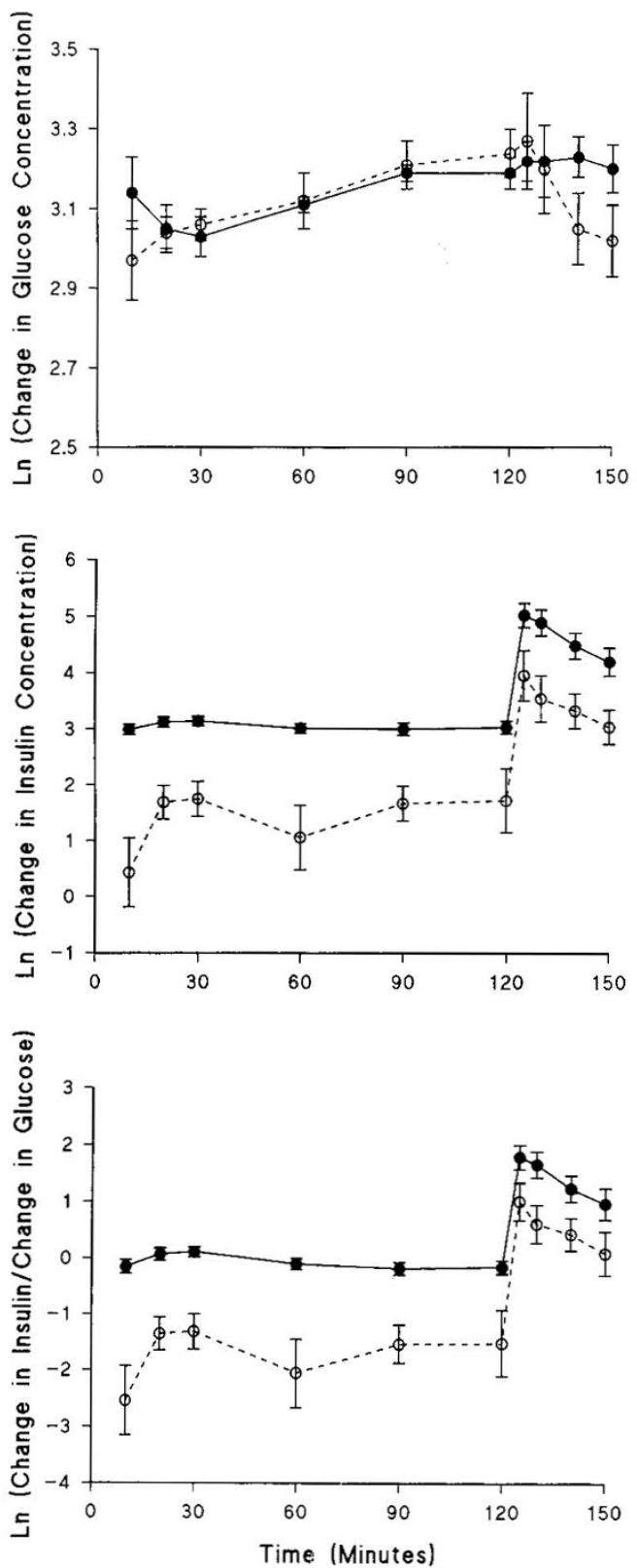

Figure 4. Study 3: Comparison of $\ln \Delta G$ (top panel), ln $\Delta I$ (middle panel), and $\ln \Delta I / \Delta G$ ratio (bottom panel) at each sampling time during period 1 (5-25 $\mathrm{min})$, period $2(30-120 \mathrm{~min})$, and period $3(125-150 \mathrm{~min})$ for the control ( and hyperglycemic animals $(O)$. Data are shown as mean \pm SEM.

respectively). EC versus $H G$ differences between $\ln \Delta I$ and $\ln$ $\Delta I / \Delta G$ were greater in study 2 than in study $1(p=0.006 \ln \Delta I$; $p=0.0036 \ln \Delta l / \Delta G)$. As in study 1 , in both groups blood $\mathrm{O}_{2}$ saturation and content tended to decrease (but not significantly), lactate concentrations increased significantly by the third period, and $\mathrm{pH}$ did not change. There were no between-group differences for these variables and no differences from study 1 .

During study 3 (14-17 d of hyperglycemia), $G$ was greater in all three periods in the $\mathrm{HG}$ group compared with the EC group, but $\Delta G$ was not, and both $I$ and $\Delta l$ were significantly less in the HG group in all three periods (Table 4). The EC versus $\mathrm{HG}$ group differences between $\ln \Delta I$ and $\ln \Delta I / \Delta G$ were greater in study 3 than in study $2(p<0.0001 \ln \Delta I ; p=$ $0.0011 \ln \Delta I / \Delta G)$. As shown in Figure 4, values for ln $\Delta G$ in

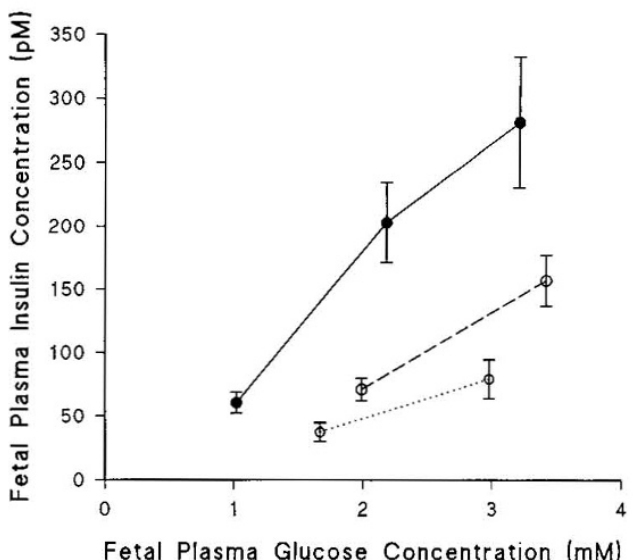

Figure 5. Relationship between plasma insulin concentration and plasma glucose concentration. The top line $(-0)$ shows the mean \pm SEM values for plasma insulin concentration at time zero, 30-120 min, and 135-240 min for six control animals during study 2. Comparative data are shown for the hyperglycemic animals for time zero and 30-120 min during study 2 (middle line: $\bigcirc-\cdots-($ ) and study 3 (bottom line: $\bigcirc \cdots \cdots . . .$. ).

all three periods were not different between the two groups ( $p$ $=0.57$ period $1, p=0.53$ period 2 , and $p=0.28$ period 3$)$. In all three periods $\ln \Delta I$ was less in the HG group $(p<0.0001$ for each period), as were $\ln \Delta I / \Delta G$ ratios ( $p<0.0001$ for periods 1 and 2, $p=0.0001$ for period 3). As in studies 1 and 2 , blood $\mathrm{O}_{2}$ saturation and content tended to decrease (but not significantly), lactate concentration increased significantly by period 3, and $\mathrm{pH}$ did not change; there were no significant between-group differences for these variables.

Figure 5 shows the relationship between study period mean steady state insulin concentrations and glucose concentrations in the subgroup of control animals that was studied at time zero and during two glucose clamp periods during study 2 (30-120 $\mathrm{min}$ and 135-240 $\mathrm{min}$ ) compared with the time zero and period 2 (30-120 min) values for the hyperglycemic group in studies 2 and 3. The increase in insulin concentration with glucose concentration in the control subgroup was curvilinear (insulin $=-206+16.0[G]-0.13[G]^{2} \pm 82$ ). The second degree coefficient was significantly negative $(p<0.001)$ indicating a decelerating relationship between insulin and glucose above a glucose concentration of approximately $2.2 \mathrm{mM}$. The mean slope (calculated as the derivative, $\Delta[I] / \Delta[G]$, for the quadratic equation) for the EC animals (Fig. 5, top line) was significantly greater $(p=0.001)$ than the slope of $I$ versus $G$ for the study $3 \mathrm{HG}$ group (bottom line, $I=2.52+1.43[G] \pm 83, p=0.12$ different from zero slope) and borderline significantly greater ( $p=0.07$ ) than the slope of $I$ versus $G$ of the study $2 \mathrm{HG}$ group (middle line, $I=-62.1+3.56[G] \pm 83, p<0.001$ different from zero slope). The slope of $I$ versus $G$ for the HG group in study 3 was significantly less than that in study $2(p=0.04)$.

Table 5 shows results of measured variables during the glucose clamp for the post-hyperglycemic study (fetuses that had been hyperglycemic for 7-10 d and then euglycemic for 7-10 d, compared with control animals of the same gestational age). There were no differences between these groups for zero time values or increases in glucose and insulin concentrations or changes in other biochemical and hematologic variables during the glucose clamp and after the arginine infusion. 
CARVER ET AL.

Table 4. Study 3 glucose clamp: steady state period mean \pm SEM values for biochemical and hematologic variables

\begin{tabular}{|c|c|c|c|c|c|c|}
\hline \multirow[b]{2}{*}{ Variable } & \multicolumn{2}{|c|}{ Period 1 (5-25 min) } & \multicolumn{2}{|c|}{ Period $2(30-120 \mathrm{~min})$} & \multicolumn{2}{|c|}{ Period $3(125-150 \mathrm{~min})$} \\
\hline & $\begin{array}{l}\text { Control } \\
(n=8)\end{array}$ & $\begin{array}{c}\text { Hyperglycemic } \\
(n=6)\end{array}$ & $\begin{array}{l}\text { Control } \\
(n=8)\end{array}$ & $\begin{array}{l}\text { Hyperglycemic } \\
(n=6)\end{array}$ & $\begin{array}{l}\text { Control } \\
(n=8)\end{array}$ & $\begin{array}{c}\text { Hyperglycemic } \\
(n=6)\end{array}$ \\
\hline Glucose (mM) & $2.25 \pm 0.09$ & $3.06 \pm 0.12^{* *}$ & $2.27 \pm 0.09$ & $2.98 \pm 0.12^{* *}$ & $2.40 \pm 0.10$ & $3.02 \pm 0.08^{* *}$ \\
\hline$\Delta$ Glucose $(\mathrm{mM})$ & $1.26 \pm 0.10$ & $1.13 \pm 0.08$ & $1.27 \pm 0.03$ & $1.32 \pm 0.07$ & $1.41 \pm 0.07$ & $1.41 \pm 0.12$ \\
\hline Insulin (pM) & $189 \pm 14$ & $65 \pm 13 * *$ & $188 \pm 15$ & $80 \pm 15^{* *}$ & $824 \pm 138$ & $326 \pm 107 * *$ \\
\hline$\Delta$ Insulin $(\mathrm{pM})$ & $131 \pm 10$ & $28 \pm 8^{* *}$ & $131 \pm 10$ & $42 \pm 10^{* *}$ & $766 \pm 136$ & $289 \pm 103 * *$ \\
\hline $\mathrm{O}_{2}$ saturation $(\%)$ & $50.1 \pm 3.3$ & $47.4 \pm 4.6$ & $48.4 \pm 3.6$ & $40.4 \pm 5.1$ & $42.2 \pm 4.8$ & $40.2 \pm 4.9$ \\
\hline $\mathrm{O}_{2}$ content $(\mathrm{mM})$ & $3.20 \pm 0.23$ & $3.02 \pm 0.46$ & $2.80 \pm 0.26$ & $2.55 \pm 0.23$ & $2.51 \pm 0.28$ & $2.52 \pm 0.30$ \\
\hline $\mathrm{pH}$ & $7.33 \pm 0.02$ & $7.33 \pm 0.02$ & $7.31 \pm 0.01$ & $7.32 \pm 0.02$ & $7.31 \pm 0.01$ & $7.32 \pm 0.02$ \\
\hline Lactate $(\mathrm{mM})$ & $1.43 \pm 0.16$ & $1.50 \pm 0.16$ & $1.88 \pm 0.30$ & $1.67 \pm 0.30$ & $2.30 \pm 0.29$ & $1.99 \pm 0.32$ \\
\hline
\end{tabular}

$* p<0.05$ hyperglycemic different from control, same period.

** $p<0.01$ hyperglycemic different from control, same period.

Table 5. Post-HG study glucose clamp: steady state period mean \pm SEM values for biochemical and hematologic variables $($ control, $\mathrm{n}=$ 8; post $-H G, \mathrm{n}=6$ )

\begin{tabular}{|c|c|c|c|c|c|c|}
\hline \multirow[b]{2}{*}{ Variable } & \multicolumn{2}{|c|}{ Period $1(5-25 \mathrm{~min})$} & \multicolumn{2}{|c|}{ Period $2(30-120 \mathrm{~min})$} & \multicolumn{2}{|c|}{ Period $3(125-150 \mathrm{~min})$} \\
\hline & Control & Post-HG & Control & Post-HG & Control & Post-HG \\
\hline Glucose (mM) & $2.25 \pm 0.09$ & $2.46 \pm 0.17$ & $2.27 \pm 0.09$ & $2.59 \pm 0.19$ & $2.40 \pm 0.10$ & $2.67 \pm 0.18$ \\
\hline$\Delta$ Glucose $(\mathrm{mM})$ & $1.26 \pm 0.10$ & $1.45 \pm 0.10$ & $1.27 \pm 0.03$ & $1.58 \pm 0.11$ & $1.41 \pm 0.07$ & $1.66 \pm 0.10$ \\
\hline Insulin $(\mathrm{pM})$ & $189 \pm 14$ & $212 \pm 34$ & $188 \pm 15$ & $231 \pm 38$ & $824 \pm 138$ & $726 \pm 96$ \\
\hline$\Delta$ Insulin $(\mathrm{pM})$ & $131 \pm 10$ & $150 \pm 21$ & $131 \pm 10$ & $169 \pm 24$ & $766 \pm 136$ & $695 \pm 59$ \\
\hline $\mathrm{O}_{2}$ saturation (\%) & $50.1 \pm 3.3$ & $43.6 \pm 4.6$ & $48.4 \pm 3.6$ & $41.2 \pm 5.0$ & $42.2 \pm 4.8$ & $37.1 \pm 4.6$ \\
\hline $\mathrm{O}_{2}$ content $(\mathrm{mM})$ & $3.20 \pm 0.23$ & $2.70 \pm 0.22$ & $2.80 \pm 0.26$ & $2.50 \pm 0.23$ & $2.51 \pm 0.28$ & $2.25 \pm 0.23$ \\
\hline $\mathrm{pH}$ & $7.33 \pm 0.02$ & $7.35 \pm 0.01$ & $7.31 \pm 0.01$ & $7.32 \pm 0.02$ & $7.31 \pm 0.01$ & $7.32 \pm 0.02$ \\
\hline Lactate (mM) & $1.43 \pm 0.16$ & $1.40 \pm 0.15$ & $1.88 \pm 0.30$ & $2.03 \pm 0.31$ & $2.30 \pm 0.29$ & $2.48 \pm 0.28$ \\
\hline
\end{tabular}

There were no differences between control and post-HG groups for any variable in any study.

Period 3 mean plasma arginine concentrations were $1.85 \pm$ $0.30 \mathrm{mM}$ in the $\mathrm{HG}$ group and $2.28 \pm 0.35 \mathrm{mM}$ in the EC group averaged over all three studies; there were no differences among the mean arginine concentrations in the three studies for each group.

Maternal pancreatic insulin concentrations $(1.26 \pm 0.36$ $\mathrm{nmol} / \mathrm{g} \mathrm{HG} ; 0.84 \pm 0.30 \mathrm{nmol} / \mathrm{g} \mathrm{EC})$ and fetal pancreatic insulin concentrations $(9.18 \pm 1.86 \mathrm{nmol} / \mathrm{g} \mathrm{HG} ; 7.80 \pm 1.74$ $\mathrm{nmol} / \mathrm{g} \mathrm{EC)}$ were not significantly different between $\mathrm{HG}$ and $\mathrm{EC}$ animals.

\section{DISCUSSION}

The most important observation of the current study is that the ability of the pancreas to produce higher concentrations of insulin in response to hyperglycemia in these fetal sheep was significantly attenuated by chronic, relatively marked, and constant fetal hyperglycemia. This contrasts with what is believed to occur in human fetuses of pregnant diabetic mothers in whom direct and indirect evidence indicates that insulin secretion is increased under most conditions, including rapid increases of maternal and fetal glucose concentrations (18). In the fetal sheep in the present study, however, in spite of 7-10 $\mathrm{d}$ of hyperglycemia, fetal plasma insulin concentrations of the HG fetuses were not significantly different from the values in the same animals before starting the glucose infusions, or the control fetuses of the same gestational age. This produced a lower than normal $I / G$ ratio as evidence that sustained hyperglycemia of over twice normal values was unable to produce higher plasma concentrations of insulin. In contrast, previous studies in fetal sheep that were infused with glucose to variable but comparable levels of hyperglycemia showed variable but significantly increased concentrations of insulin over the first $1-3 \mathrm{~d}$ of hyperglycemia $(5,7)$. Furthermore, although the HG fetuses in the present study were able to respond to an acute glucose challenge by increasing their plasma insulin concentrations, the increase in insulin concentration in the HG group was significantly less than in the EC group, during the initial response to hyperglycemia (5-25 $\mathrm{min}$ ) and during the period $(30-120 \mathrm{~min})$ of steady state insulin secretion. Thus, both basal insulin concentrations and glucose-stimulated insulin secretion were attenuated for the degree of hyperglycemia.

After an additional 7-10 d of chronic hyperglycemia (study 3 ), the HG fetuses developed an even greater attenuation of insulin secretion in response to acute hyperglycemia demonstrated by significantly lower initial (5-25 $\mathrm{min}$ ) and steady state (30-120 min) values of $I, \Delta I$, and $\Delta I / \Delta G$. These results indicate that chronic hyperglycemia in fetal sheep induces a requirement for an increased concentration of glucose to produce even normal basal concentrations of plasma insulin, and a progressively increasing increment of glucose concentration to induce insulin secretion to the same extent as in normal, euglycemic fetuses. This change is shown in Figure 5 as a shift to the right and progressive flattening of the insulin-glucose concentration relationship.

The comparability of the control and hyperglycemic fetuses at the initial study makes it unlikely that the changes observed in the hyperglycemic animals were due to a unique group of animals. Also, because the chronically hyperglycemic fetuses 
retained the ability to secrete significant amounts of insulin in response to arginine at the 7-10-d study (study 2), it is unlikely that with this duration of hyperglycemia the observed reduction in insulin secretion in response to acute hyperglycemia is due to a non-glucose mechanism. Because the ability of the pancreas to secrete insulin in response to arginine is maintained even when insulin secretion to glucose is markedly attenuated, it is more probable that insulin secretion and not insulin production is inhibited.

By 14-17 d of hyperglycemia, however, even arginine stimulation of insulin secretion was reduced in the hyperglycemic fetuses. The mechanism for this reduction in arginineinduced insulin secretion is unknown. A decreased production of insulin is unlikely to explain this late change as the pancreatic insulin concentrations that were measured on autopsy specimens immediately at the end of the glucose clamp in study 3 were similar in the euglycemic and hyperglycemic fetuses.

The fetal sheep pancreas also responds to other insulin secretagogues such as arginine, leucine, alanine, and theophylline, even when there is little or no response to glucose $(9,19)$. These other insulin secretagogues are thought to stimulate insulin secretion via mechanisms different from those specific to glucose (20). The insulin response to arginine has been shown to increase with gestational age (19). The data in the present study confirm the ability of the fetal sheep to secrete insulin in response to arginine, but there was no measurable increase in arginine-stimulated insulin secretion with advancing gestational age over the brief age range studied (122-138 d). The decreased insulin secretion in response to arginine seen in the HG fetuses compared with controls during the third study after at least 2 wk of hyperglycemia was unlikely to be due to lower arginine concentrations obtained in the hyperglycemic fetuses compared with controls as preliminary data in our laboratory indicate that both groups received doses of arginine that were well above those that produced a maximum effect of arginine on insulin secretion in fetal sheep, regardless of the level of glycemia (12).

Regarding the mechanism for the hyperglycemia-associated reduction in glucose-stimulated insulin secretion, previous studies have shown that chronic hyperglycemia in fetal sheep produces highly variable increases in plasma insulin concentrations that become increasingly variable and lower in association with increasing degrees of hypoxia $(6,7,21,22)$. Such results have led to the speculation that hypoxia may inhibit insulin secretion directly $(6,7,21,22)$ or via hypoxia-induced catecholamine secretion $(8,9)$. In the present study, however, there were no significant differences in blood oxygen saturation or blood oxygen content between the EC and HG fetuses in any of the three studies. This indicates that factors other than hypoxia may have been responsible for the progressive decrease in insulin secretion in response to chronic hyperglycemia in the present study, although a specific effect of hypoxia was not tested for and cannot be ruled out. Specific tests of the role of catecholamines or other stress-responsive hormones such as glucagon and cortisol remain to be determined.

Published data have shown that fetal sheep can secrete insulin in response to acute hyperglycemia as early as $110 \mathrm{~d}$
(75\%) gestation (19) and preliminary studies in our laboratory have put this earliest response at about $70 \mathrm{~d}$ or $50 \%$ gestation (23). At somewhat later gestation, this response has been shown to persist for up to $5 \mathrm{~d}$ with continuous glucose infusion, but the response begins to decrease after a few days (5-7). In sheep, maternal diabetes with hyperglycemia induced by streptozotocin or alloxan has been shown to result in fetal hyperglycemia but not fetal hyperinsulinemia, with basal insulin concentrations comparable to those reported in this study (3, 4). At least in the alloxan studies, the fetuses developed normal insulin secretion after birth, indicating but not proving that hyperglycemia in the fetus and not maternally acquired alloxan was responsible for the suppression of fetal insulin secretion (4). In the present study, effects of diabetogenic agents were not present, emphasizing the glucose specificity in the reduction of insulin secretion in response to chronic hyperglycemia. In this regard, rat $\beta$-cells exposed to mild hyperglycemia in vivo have been shown to have an exaggerated insulin response to an elevated glucose concentration in vitro, whereas $\beta$-cells exposed to marked hyperglycemia in vivo have an attenuated insulin response in vitro $(24,25)$; this attenuation of insulin secretion was reversed when the cells were grown in a low glucose medium.

The present study also shows that hyperglycemia-associated suppression of insulin secretion is reversible upon returning the fetus to a euglycemic state. Reversibility does not preclude the potential for long-term effects of the hyperglycemic state and its suppression of insulin secretion. In fact, in a preliminary report, maternal hyperglycemia induced by glucose infusion during the last week of gestation resulted in a diminished postnatal increase in plasma insulin concentration in the lamb (26). Reversibility also is important to consider in view of studies which have shown a tendency to develop gestational diabetes in the female offspring of diabetic pregnant rats (27, 28). The present data also may help to explain the considerable variability found in human infants of diabetic mothers for postnatal changes in glucose concentration and glucose utilization (18).

As a result of the attenuated insulin secretion, basal plasma glucose concentrations in the HG fetuses were significantly greater relative to those of the mother than in the EC fetuses. Two mechanisms may account for this change. First, fetal hyperglycemia has the potential for down-regulating fetal tissue glucose utilization, particularly in insulin-sensitive tissues (29). Second, with lower than expected insulin concentrations, fetal glucose clearance also is less than expected (15). In both cases, fetal glucose concentration will increase relative to that of the mother, to a value higher than would have been present had insulin concentration and perhaps insulin action been normal. An increase in fetal glucose concentration decreases the maternal-to-fetal glucose concentration gradient and, in turn, fetal glucose uptake from the placenta, providing less carbon substrate for fetal oxidative metabolism and growth. Fetal insulin deficiency has been shown to reduce the rate of fetal growth (30). The present studies provide evidence, therefore, that hyperglycemic suppression of fetal insulin secretion also has the potential to limit an increase in the rate of fetal growth in spite of hyperglycemia. By extrapolation, it also is 
possible that such a mechanism, if operative in human fetuses, could to help explain part of the variation in fetal weight among diabetic pregnancies and the reduction in fetal weight that has been observed in pregnancies of some women with more severe and long-standing cases of diabetes mellitus (3133), as well as a relatively lesser degree of fetal macrosomia at term among pregnant women with insulin-dependent diabetes compared with gestational diabetics (34).

Because of the importance of insulin in the regulation of fetal growth, maturation, metabolism, and specific morbidity and mortality in diabetic pregnancies, further investigations are warranted to elucidate the mechanisms by which fetal glucose regulates the release of insulin. The data presented in the current study indicate, however, that glucose-induced suppression of fetal pancreatic insulin secretion may help to explain some of the considerable variability in fetal growth rate that occurs in diabetic pregnancies, either experimentally in animals or pathologically in humans.

Acknowledgments. The authors express their appreciation to Gary Zerbe, Ph.D., Sheila Gardner, and Joleen Borgerding for their time and effort in assisting with the statistical analysis of the data in this manuscript.

\section{REFERENCES}

1. Philipps AF, Carson BS, Meschia G, Battaglia FC 1978 Insulin secretion in fetal and newborn sheep. Am J Physiol 235:E467-E474

2. Davis JR, Beck P, Colwill JR, Makowski EL, Meschia G, Battaglia FC 1974 Insulin response to fructose and glucose infusions into the sheep fetus. Proc Soc Exp Biol Med 136:972-975

3. DiGiacomo JE, Hay Jr WW. 1990 Effect of chronic hyperglycemia on ovine fetal pancreatic insulin secretion. Pediatr Res 27:42A(abstr)

4. Lips JP, Henk WJ, Crevels J, Eskes TK. 1988 Chronic hyperglycemia and insulin concentrations in fetal lambs. Am J Obstet Gynecol 159:247-251

5. Bassett JM, Madill D 1974 Influence of prolonged glucose infusions on plasma insulin and growth hormone concentrations of foetal lambs. J Endocrinol 62:299-309

6. Philipps AF, Dubin JW, Matty PJ, Raye JR 1982 Arterial hypoxemia and insulinemia in the chronically hyperglycemic fetal lamb. Pediatr Res 16:653-658

7. Philipps AF, Porte PJ, Stabinsky S, Rosenkrantz TS, Raye JR 1984 Effects of chronic fetal hyperglycemia upon oxygen consumption in the ovine uterus and conceptus. J Clin Invest 74:279-286

8. Jackson BT, Cohn HE, Morrison SH, Baker RM, Piasecki GJ 1993 Hypoxia-induced sympathetic inhibition of fetal plasma insulin response to hyperglycemia. Diabetes 42:1621-1625

9. Fowden A 1980 Effects of adrenaline and amino acids on the release of insulin in the sheep fetus. J Endocrinol 87:113-121

10. Aerts L, Holemans K, Van Assche FA 1990 Maternal diabetes during pregnancy: consequences for the offspring. Diabetes Metab Rev 6:147-167
11. Kervran A, Randon J 1980 Development of insulin release by fetal rat pancreas in vitro. Diabetes 29:673-678

12. Gresores A, Anderson SM, Hood D, Hay Jr WW. 1995 Independent effects of arginine and glucose on ovine fetal insulin secretion. J Soc Gynecol Invest 2:330 (abstr)

13. Brinsmeade MW, Thorburn GD 1982 Effect of streptozotocin on fetal lambs in mid-pregnancy. Aust J Biol Sci 35:517-525

14. Hay WW Jr, Meznarich HK, Fowden A 1989 The effect of streptozotocin on rates of glucose utilization, oxidation and production in the sheep fetus. Metabolism 38:30-37

15. Hay Jr WW, Meznarich HK, DiGiacomo JE, Hirst K, Zerbe G 1988 Effects of insulin and glucose concentrations on glucose utilization in fetal sheep. Pediatr Res 23:381387

16. Laird NM, Ware JH 1982 Random effects models for longitudinal data. Biometrics 38:963-974

17. Jenrich RI, Schluchter MD 1986 Unbalanced repeated measures models with structured covariance matrices. Biometrics 42:805-820

18. Cowett RM 1992 Hypoglycemia and hyperglycemia in the newborn. In: Polin RA, Fox WW (eds) Fetal and Neonatal Physiology. WB Saunders, Philadelphia, pp 406-418

19. Fowden A 1980 Effects of arginine and glucose on the release of insulin in the sheep fetus. J Endocrinol 85:121-129

20. Liang Y, Matschinsky FM 1994 Mechanism of action of nonglucose insulin secretagogues. Annu Rev Nutr 14:59-81

21. Milley JR, Rosenberg AA, Philipps AF, Molteni RA, Jones Jr MD, Simmons MA 1984 The effect of insulin on ovine fetal oxygen. Am J Obstet Gynecol 149:673-678

22. Philipps AF, Dubin JW, Raye JR 1981 Fetal metabolic response to endogenous insulin release. Am J Obstet Gynecol 139:441-445

23. Molina RD, Carver TD, Hay Jr WW 1993 Ontogeny of insulin effect in fetal sheep. Pediatr Res 34:654-660

24. Takao F, Kagawa S, Sakamoto K, Matsuoko A 1988 Effect of maternal hyperglycemia on insulin secretion by monolayer cultures of pancreatic cells from neonatal rats: a perifusion study. J Endocrinol 119:493-499

25. Kervran A, Guillaume M, Jost A 1978 The endocrine pancreas of the fetus of diabetic pregnant rat. Diabetologia 15:387-393

26. Clarke L, Andrews DC, Crompton LA, Lomax MA, Symonds ME 1994 Effect of maternal glucose infusion during late gestation on the catecholamine content and thermogenic activity of brown adipose tissue in the newborn lamb. J Physiol 467:291(abstr)

27. Aerts L, Holemans K, Van Assche FA 1990 Maternal diabetes during pregnancy: consequences for the offspring. Diabetes Metab Rev 6:147-167

28. Oh W, Gelardi NL, Cha, C-J 1988 Maternal hyperglycemia in pregnant rats: its effect on growth and carbohydrate metabolism in the offspring. Metabolism 37:1146-1151

29. Hay Jr WW, Aldoretta PW, Carver TD 1994 Glucose-specific suppression of insulin secretion and glucose utilization in late-gestation fetal sheep. In: Cosmi, EV, Di Renzo GC (eds) Current Progress in Perinatal Medicine. Parthenon Publishing, New York, pp 497-505

30. Fowden AL 1989 The role of insulin in prenatal growth. J Dev Physiol 12:173-182

31. Kaminsky S, Sibley CP, Maresh M, Thomas CR 1991 The effects of diabetes on placental lipase activity in the rat and human. Pediatr Res 30:541-543

32. Langer O, Levy J, Brustman L, Anyaegbunam A, Merkatz R, Divon M 1989 Glycemic control in gestational diabetes mellitus-how tight is tight enough: small for gestational age versus large for gestational age? Am J Obstet Gynecol 161:646653

33. Gestation and Diabetes in France Study Group 1991 Multicenter survey of diabetic pregnancy in France. Diabetes Care 14:994-1000

34. Barada C, Izquierdo L, Gilson G, Curet L 1995 Is the blood glucose concentration related to the incidence of large for gestational age infants in patients with gestational and insulin requiring diabetes mellitus? J Soc Gynecol Invest 2:193(abstr) 